\title{
ppGpp Controlled by the Gac/Rsm Regulatory Pathway Sustains Biocontrol Activity in Pseudomonas fluorescens CHAO
}

\author{
Kasumi Takeuchi, ${ }^{1}$ Kosumi Yamada, ${ }^{2}$ and Dieter Haas ${ }^{3}$ \\ ${ }^{1}$ Division of Plant Sciences, National Institute of Agrobiological Sciences, 2-1-2 Kannondai, Tsukuba, Ibaraki 305-8602, Japan; \\ ${ }^{2}$ Graduate School of Life and Environmental Sciences, University of Tsukuba, Ibaraki 305-8572, Japan; ${ }^{3}$ Département de \\ Microbiologie Fondamentale, Université de Lausanne, $\mathrm{CH}-1015$ Lausanne, Switzerland
}

Submitted 12 February 2012. Accepted 8 July 2012.

In Pseudomonas fluorescens CHA0 and other fluorescent pseudomonads, the Gac/Rsm signal transduction pathway is instrumental for secondary metabolism and biocontrol of root pathogens via the expression of regulatory small RNAs (sRNAs). Furthermore, in strain CHA0, an imbalance in the Krebs cycle can affect the strain's ability to produce extracellular secondary metabolites, including biocontrol factors. Here, we report the metabolome of wild-type CHA0, a gacA-negative mutant, which has lost Gac/Rsm activities, and a retS-negative mutant, which shows strongly enhanced Gac/Rsm-dependent activities. Capillary electrophoresis-based metabolomic profiling revealed that the gacA and $\mathrm{retS}$ mutations had opposite effects on the intracellular levels of a number of central metabolites, suggesting that the Gac/Rsm pathway regulates not only secondary metabolism but also primary metabolism in strain CHA0. Among the regulated metabolites identified, the alarmone guanosine tetraphosphate (ppGpp) was characterized in detail by the construction of relA (for ppGpp synthase) and spoT (for ppGpp synthase/hydrolase) deletion mutants. In a relA spoT double mutant, ppGpp synthesis was completely abolished, the expression of Rsm sRNAs was attenuated, and physiological functions such as antibiotic production, root colonization, and plant protection were markedly diminished. Thus, ppGpp appears to be essential for sustaining epiphytic fitness and biocontrol activity of strain CHAO.

Pseudomonas fluorescens CHA0 is an effective biocontrol bacterium, which suppresses plant diseases by producing several extracellular enzymes and secondary metabolites with antibiotic activity in the rhizosphere. These exoproducts importantly contribute to plant protection by strain $\mathrm{CHA} 0$ and other root-colonizing Pseudomonas spp. having biocontrol activity. Mutants defective in the Gac/Rsm signal transduction pathway have a reduced ability to produce such biocontrol factors and to suppress plant diseases (Haas and Défago 2005; Kim et al. 2011).

The Gac/Rsm signal transduction pathway is initiated by the GacS/GacA two-component system (Lapouge et al. 2008). At

Corresponding author: K. Takeuchi; Telephone: +81 29838 7005; Fax: +8129838 7408; E-mail: kasumit@affrc.go.jp

* The $e$-Xtra logo stands for "electronic extra" and indicates that six supplementary figures and three supplementary tables are published online. high cell population densities, the phosphorylated GacS sensor kinase activates the cognate $\mathrm{GacA}$ response regulator, which promotes the transcription of two or more noncoding small RNAs (sRNAs) in Pseudomonas spp. In P. fluorescens CHA0, GacA positively controls the expression of three sRNAs termed RsmX, RsmY, and RsmZ. These sRNAs have a high affinity for the RNA-binding protein RsmA and, additionally, for the RsmA paralog RsmE (Heeb et al. 2002; Kay et al. 2005; Reimmann et al. 2005; Valverde et al. 2003). The RsmA and RsmE proteins repress the translation of genes involved in secondary metabolism during the trophophase (i.e., during rapid growth). When the RsmX/Y/Z sRNAs are induced in the idiophase (i.e., during restricted growth), they relieve translational repression of target genes by sequestering the RsmA and RsmE proteins, thereby allowing the synthesis of secondary metabolites (Kay et al. 2005, 2006). In P. fluorescens and $P$. aeruginosa, two additional sensors termed RetS and LadS provide input into the Gac/Rsm pathway (Goodman et al. 2009; Humair et al. 2009). RetS inhibits and LadS activates the activity of the Gac/Rsm pathway and, in this way, both sensors affect the expression of target genes and biocontrol factors (Humair et al. 2009). In P. fluorescens CHA0, evidence for physical interaction between RetS and GacS has been obtained (Workentine et al. 2009). The RetS-GacS interaction is influenced by temperature: at $35^{\circ} \mathrm{C}$, the maximum growth temperature of strain CHA0, RetS is turned into a strong GacS antagonist and biocontrol factor production is almost completely arrested (Humair et al. 2009).

In a previous study, we have shown that an imbalance in Krebs (tricarboxylic acid [TCA]) cycle functions can affect biocontrol factor production by strain $\mathrm{CHA} 0$ through altered $r s m X / Y / Z$ gene expression (Takeuchi et al. 2009). In that study, two enzymes involved in the function of the TCA cycle (i.e., fumarase $[f u m A]$ and pyruvate carboxylase $[p y c A B]$ ), were found to be key factors in the regulation of the Gac/Rsm signal transduction pathway. Furthermore, a metabolic analysis of the fum $A$ and pycAB mutants revealed changes in the levels of TCA cycle intermediates, suggesting that regulatory links exist between primary and secondary metabolism via TCA cycle function and GacA-dependent sRNAs.

In the present study, we ask to what extent the metabolomic profile of strain CHA0 will be affected in a gacA-negative mutant, which has lost Gac/Rsm activities, and in retS- and fumAnegative mutants, which show strongly enhanced Gac/Rsmdependent activities (Humair et al. 2009; Takeuchi et al. 2009). To this end, we have used a capillary electrophoresis time-offlight mass spectrometry (CE-TOFMS)-based approach, which 
provides a sensitive and reproducible analysis of a broad range of compounds (Soga et al. 2003). Among the metabolites found to be strongly regulated by the Gac/Rsm system, the intracellular alarmone guanosine tetraphosphate (ppGpp) was characterized in detail for its role in the signaling pathway and biocontrol activity.

\section{RESULTS}

\section{Metabolomic profiling of central metabolites in strain CHAO and in gacA, retS, and fumA mutants.}

To see the metabolic consequences of the loss of genes involved in the Gac/Rsm cascade, we determined the intracellular metabolome by CE-TOFMS in the wild-type CHA0 and in gacA, retS, and fumA mutants. These strains were grown in a diluted and modified glycerol-casamino acids medium (GCM), which minimizes the effects of the medium on metabolite analysis, as described previously (Takeuchi et al. 2009). In this medium, the wild type and the mutants grew equally well and showed the typical pattern of differential rsmZ-lacZ expression (i.e., enhanced expression in the $\operatorname{ret} S$ and fum $A$ mutants and downregulation in the gacA mutant) (Supplementary Fig. S1), in agreement with previous studies (Heeb et al. 2002; Humair et al. 2009; Takeuchi et al. 2009).

We identified 218 metabolites by matching their migration times in CE and molecular masses $(\mathrm{m} / \mathrm{z})$ to those of the metabolic standards (Supplementary Table S1). For each strain, the intracellular metabolite concentrations were calculated from MS peak intensities and the number of cells in the medium. Concentrations were compiled for 85 primary metabolites (Supplementary Table S2) and sorted in descending order of the ratio gacA/CHA0 or retS/CHA0. Several metabolites classified as "amino acids" (e.g., arginine, tyrosine, tryptophan, and homoserine) or "purine and pyrimidine" (e.g., the purine degra-

\section{A Sorted by $g a c A / \mathrm{CHA} 0$}

\begin{tabular}{|c|c|c|c|c|}
\hline \multirow{2}{*}{ Metabolite } & \multirow{2}{*}{ Pathway } & \multicolumn{3}{|c|}{ Ratio to WT } \\
\hline & & $\operatorname{gac} A$ & $\mathrm{retS}$ & fumA \\
\hline ppGpp divalent & Others (ppGipp biosynthesis) & 6.5 & 0.4 & 0.3 \\
\hline GABA & Amino acids (Glu, Gin, His, Pro, Arg) & 4.3 & 0.4 & 0.7 \\
\hline Sarcosine & Amino acids (Gly, Ser, Cys) & 4.2 & 5.3 & ND \\
\hline 2-Methylserine & Others & 3,9 & 1.6 & 0.8 \\
\hline Hypoxanthine & Purine, Pyrimidine & 3.2 & 0.2 & 0.7 \\
\hline Adipic acid & Others & 2.9 & 0.8 & 0.7 \\
\hline 3-Phosphoglyceric acid & Glucose degradation, Pentose-P, Krebs cycle & 2.8 & 1.7 & 1.0 \\
\hline Uric acid & Purine, Pyrimidine & 2.5 & 0.4 & 0.8 \\
\hline Ribulose 5-phosphate & Glucose degradation, Pentose-P, Krebs cycle & 2.4 & 0.8 & 0.8 \\
\hline Phosphoenolpyruvic acid & Glucose degradation, Pentose-P, Krebs cycle & 2.3 & 1.3 & 0.9 \\
\hline Homoserine & Others (Homoserine biosynthesis) & 2.2 & 1.0 & 0.4 \\
\hline Arg & Amino acids (Ghu, Gin, His, Pro, Arg) & 2.2 & 0.4 & 0.7 \\
\hline$N$-Acetylglutamic acid & Amino acids (Ghu, Gin, His, Pro, Arg) & 2.0 & 0.5 & 0.3 \\
\hline Tyr & Amino acids (Aromatic amino acids) & 2.0 & 0.8 & 0.7 \\
\hline B-Ab & Amino acids (Asp, Ah, Lys) & 2.0 & 1.0 & 0.5 \\
\hline $\mathrm{N}$-Acetylglucosamine & Nucleotide sugar, Amino sugar & 1.9 & 0.9 & 0.8 \\
\hline Quinic acid & Others (Shikimic acid pathway) & 1.9 & 0.7 & 0.9 \\
\hline 2-Phosphoglyceric acid & Giucose degradation, Pentose-P, Krebs cycle & 1.9 & 1.7 & 1.0 \\
\hline $\operatorname{Trp}$ & Amino acids (Aromatic amino acids) & 1.8 & 0.5 & 1.0 \\
\hline 4-Guanidinobutyric acid & Amino acids (Glu, Gin, His, Pro, Arg) & 1.7 & 0.4 & 1.2 \\
\hline Pipecolic acid & Amino acids (Asp, Ab, Lys) & 1.7 & 0.5 & 0.9 \\
\hline 2,6-Diaminopimelic acid & Others & 1.7 & 1.0 & 1.0 \\
\hline Urea & Amino acids (Glu, Gin, His, Pro, Arg) & 1.7 & 0.8 & 0.7 \\
\hline 2-Deoxyglucose 6-phosphate & Others & 1.7 & 0.6 & 0.6 \\
\hline Isobutyryl CoA divalent & Amino acids (Branched chain amino acids) & 1.6 & 0.4 & 1.0 \\
\hline UDP-glucuronic acid & Nucleotide sugar, Amino sugar & 1.6 & 0.8 & 0.8 \\
\hline Cysteine glutathione disulphide & Others & 1.6 & 1.1 & 1.1 \\
\hline dCTP & Purine, Pyrimidine & 1.6 & 0.9 & 0.9 \\
\hline Allantoic acid & Purine, Pyrimidine & 1.6 & 0.8 & 1.0 \\
\hline $\mathrm{N}$-Acetylornithine & Amino acids (Glu, Gin, His, Pro, Arg) & 1.5 & 0.4 & 0.3 \\
\hline Acetyl CoA divalent & Glucose degradation, Pentose-P, Krebs cycle & 1.5 & 1.6 & 1.0 \\
\hline dCDP & Purine, Pyrimidine & 1.5 & 0.6 & 0.7 \\
\hline
\end{tabular}

dation products hypoxanthine, urate, and allantoate) were more abundant in the gacA mutant but less abundant in the retS and fumA mutants, by comparison with the wild type (Fig. 1A). Conversely, more than half of the metabolites whose levels were higher in the retS mutant were lower in the gacA mutant, always by comparison with the wild type (Fig. 1B). These results indicate that GacA and RetS regulate central metabolism in strain CHA0 divergently and to a considerable extent. Overall, the metabolomic pattern of the retS mutant was similar to that of the fumA mutant, reflecting their phenotypic similarities, although several deviating responses could also be seen (Fig. $1 \mathrm{AB})$. Such similarities and differences of metabolic states between the strains were also visualized by a principal component analysis using a two-dimensional score plot. Again, the ret $S$ and fumA mutants were found to be in close positions, whereas the gacA mutant revealed an obvious metabolic separation from the other three strains (Supplementary Fig. S2). The fumarate pool was increased in the fumA mutant, supporting our results obtained previously (Takeuchi et al. 2009), but not in the retS mutant, suggesting that fumarate and lack of RetS can have distinct effects on the activation of the Gac/Rsm signal transduction pathway.

\section{ppGpp analysis and construction of relA and spoT mutants.}

Among the metabolites that differentially accumulated in the gacA and retS mutants, the intracellular alarmone ppGpp caught our attention because i) ppGpp is the metabolite that was most strongly regulated by GacA (Fig. 1A) and ii) ppGpp is a signaling molecule involved in the LetS/LetA and BarA/UvrY systems (which are homologous to GacS/GacA) in Legionella pneumophila and Escherichia coli, respectively (Edwards et al. 2011; Molofsky and Swanson 2004). Moreover, ppGpp is a regulator of virulence in various bacteria, besides mediating

\section{B Sorted by $\mathrm{retS} / \mathrm{CHA} 0$}

\begin{tabular}{|c|c|c|c|c|}
\hline \multirow{2}{*}{ Metabolite } & \multirow{2}{*}{ Pathway } & \multicolumn{3}{|c|}{ Ratio to WT } \\
\hline & & gacA & rets & fumA \\
\hline 3-Hydroxyaspartic acid & Others & ND & 9.6 & 0.4 \\
\hline Sarcosine & Amino acids (Gly, Ser, Cys) & 4.2 & 5.3 & ND \\
\hline$N, N$-Dimethylglycine & Amino acids (Gly, Ser, Cys) & 0.15 & 4.4 & 0.2 \\
\hline 2,4-Diaminobutyric acid & Others & ND & 3.7 & 1.9 \\
\hline $\mathrm{N}$-Acetylaspartic acid & Amino acids (Asp, Ala, Lys) & 0.7 & 2.3 & 0.6 \\
\hline Nicotinamide & Nicotinic acid, Nicotinamide & 0.3 & 2.3 & 2.6 \\
\hline Hydroxyproline & Amino acids (Glu, Gin, His, Pro, Arg) & 0.2 & 1.9 & 0.3 \\
\hline 3-Phosphoglyceric acid & Glucose degradation, Pentose-P, Krebs cycle & 2.8 & 1.7 & 1.0 \\
\hline Betaine & Amino acids (Gly, Ser, Cys) & 0.2 & 1.7 & 0.5 \\
\hline Phe & Amino acids (Aromatic amino acids) & 0.6 & 1.7 & 1.3 \\
\hline 2-Phosphoglyceric acid & Glucose degradation, Pentose-P, Krebs cycle & 1.9 & 1.7 & 1.0 \\
\hline Phenylhydrazine & Others & ND & 1.6 & 1.6 \\
\hline Acetyl $\mathrm{COA}$ divalent & Glucose degradation, Pentose-P, Krebs cycle & 1.5 & 1.6 & 1.0 \\
\hline 2-Methylserine & Others & 3.9 & 1.6 & 0.8 \\
\hline Malonyl CoA divalent & Glucose degradation, Pentose-P, Krebs cycle & 0.8 & 1.5 & 1.3 \\
\hline $\begin{array}{l}\text { 2-Amino-2-(hydroxymethyl)-1,3- } \\
\text { propanediol }\end{array}$ & Others & ND & 1.5 & 1.8 \\
\hline 3-Aminoisobutyric acid & Amino acids (Branched chain amino acids) & 0.8 & 1.5 & 1.8 \\
\hline
\end{tabular}

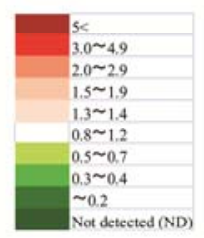

Fig. 1. Comparison of the metabolomic profiles in Pseudomonas fluorescens CHA0 and its gacA, retS, and fumA mutants. A, Metabolites upregulated in the gacA mutant and $\mathbf{B}$, metabolites upregulated in the ret $S$ mutant were compared with the wild-type CHA0. Metabolite levels were sorted in descending order of fold-change values in each mutant. Red color increments indicate enhanced levels and green indicates attenuated levels. 
the classical stringent response (Braeken et al. 2006; Dalebroux et al. 2010; Potrykus and Cashel 2008). The cellular ppGpp concentration is controlled by two enzymes, RelA (ppGpp synthase) and SpoT (ppGpp synthase/hydrolase, bifunctional) (Potrykus and Cashel 2008). In the fully sequenced strain Pf-5 of $P$. fluorescens, which is very closely related to strain $\mathrm{CHA0}$, the genes of PFL_4446 and PFL_6063 are annotated as relA and spoT, respectively (Pseudomonas Genome Database). To investigate the role of ppGpp in $\mathrm{CHA} 0$, we generated chromosomal relA (PFL_4446) and spoT (PFL_6063) deletion mutants (Supplementary Fig. S3). We also constructed a relA spoT double mutant, a gacA relA double mutant, and a gacA relA spoT triple mutant.

Intracellular ppGpp levels were determined in each strain by HPLC (Table 1). The concentration of ppGpp was $7.5 \pm 3.6$ pmol per optical density at $600 \mathrm{~nm}\left(\mathrm{OD}_{600}\right)$ in the wild-type $\mathrm{CHA} 0$ grown in diluted and modified GCM to $\mathrm{OD}_{600}=1.7$ (one $\mathrm{OD}_{600}$ unit corresponds to approximately $1.0 \times 10^{9}$ cells $\left./ \mathrm{ml}\right)$. In all relA-negative mutants, ppGpp accumulation was below the detection limit of $0.5 \mathrm{pmol} / \mathrm{OD}_{600}$, suggesting that RelA is likely to be the major source of ppGpp under these conditions. By contrast, the spoT single mutant showed a slightly higher level of ppGpp than that in the wild type; this effect was significant at $P<0.1$ but not at $P<0.05$ (Table 1).

In $E$. coli, a completely ppGpp-defective mutant is unable to grow on glucose minimal media because of auxotrophic requirements (Murphy and Cashel 2003). When the relA mutant and the relA spoT double mutant of $P$. fluorescens were compared for growth on an M9 glucose plate, a clear-cut difference was observed. Whereas the relA mutant could grow on minimal medium with glucose, the relA spoT double mutant was strongly handicapped (Supplementary Fig. S4), suggesting that the relA spoT mutant was a ppGpp null mutant, whereas the relA mutant might contain residual amounts of ppGpp, which could not be detected by high-performance liquid chromatography (HPLC). We also tested glycerol, mannitol, and fructose as a sole carbon source and found that the relA spoT double mutant had a growth handicap in each case (data not shown); thus, the mutant phenotype was not specific to glucose. We should also point out that pppGpp (guanosine pentaphosphate), which is a minor product of RelA in E. coli and Pseudomonas spp. (Boes et al. 2008; Manuel et al. 2011; Potrykus and Cashel 2008), was below detection in our nonradioactive assays.

Confirming the metabolomic profiles (Fig. 1A), we detected an elevated ppGpp concentration in the gacA mutant CHA89 and a lower concentration in the retS mutant CHA1202, by

Table 1. Comparison of intracellular guanosine tetraphosphate (ppGpp) concentrations in Pseudomonas fluorescens CHA0 and its mutants

\begin{tabular}{|c|c|c|}
\hline Strain & Genotype $^{\mathrm{y}}$ & 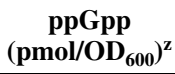 \\
\hline CHAO & Wild type & $7.5 \pm 3.6$ \\
\hline CHA89 & gacA $:: \mathrm{Km}^{\mathrm{r}}$ & $25.9 \pm 11.3 *$ \\
\hline CHA0relA & $\Delta$ relA & $<0.5$ \\
\hline CHA0spoT & $\Delta$ spot & $10.2 \pm 1.8 * *$ \\
\hline CHA0relAspoT & $\Delta$ relA $\triangle$ spoT & $<0.5$ \\
\hline CHA89relA & gacA $:: \mathrm{Km}^{\mathrm{r}} \Delta$ relA & $<0.5$ \\
\hline CHA89relAspoT & gacA:: $\mathrm{Km}^{\mathrm{r}} \Delta$ relA $\Delta$ spoT & $<0.5$ \\
\hline CHA19 & $\Delta g a c S$ & $15.0 \pm 6.8^{*}$ \\
\hline CHA1202 & $\Delta r e t S$ & $5.2 \pm 2.6 * * *$ \\
\hline CHA1009 & 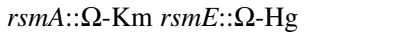 & $2.5 \pm 1.6^{*}$ \\
\hline CHA1008 & 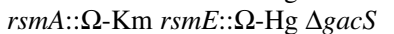 & $2.1 \pm 1.9^{*}$ \\
\hline
\end{tabular}

\footnotetext{
${ }^{\mathrm{y}} \mathrm{Km}^{\mathrm{r}}$ indicates resistant to kanamycin.

${ }^{\mathrm{z}}$ Data are presented as averages of three replicates \pm standard deviation, except for those of CHA0 (nine replicates) and CHA0spoT (six replicates). $\mathrm{OD}_{600}=$ optical density at $600 \mathrm{~nm} ; *$, **, and *** indicate values significantly different from those in CHA0 at $P<0.05,0.1$, and 0.3 , respectively $(t$ test).
}

comparison with the wild-type CHA0; the effect of the retS mutation was significant at $P<0.3$ but not at $P<0.05$ (Table 1 ). To answer the question of whether ppGpp accumulation occurs in a Gac/Rsm-dependent manner, we measured ppGpp in the gacS mutant CHA19, in the rsmA rsmE double mutant CHA1009, and in the gacS rsmA rsmE triple mutant CHA1008. The gacS mutant showed an increased level of ppGpp compared with the wild type, which is consistent with $\mathrm{GacS}$ being the cognate sensor of the GacA response regulator, although the effect of the gacS mutation was weaker than that of the gacA mutation (Table 1). The rsmA rsmE null mutations resulted in a decreased ppGpp level and canceled the positive effect of the gacS mutation in strain CHA1008 (Table 1), suggesting that the $\mathrm{GacS} / \mathrm{GacA}$ system negatively regulates intracellular ppGpp concentrations via the RsmA/RsmE proteins.

\section{A gacA mutant exhibits increased expression of a relA $=$ lacZ fusion.}

To determine whether the elevated level of ppGpp observed in the gacA mutant may be due to a different expression level of relA, we constructed a translational relA'- $\{a c Z$ fusion (Supplementary Fig. S5) and compared its expression in the wild type and in gacA and retS mutants (Fig. 2). While the retS mutation had little effect, we observed an increased level of relA expression in the gacA mutant at high cell densities, suggesting that GacA-dependent regulation of relA may account, at least in part, for the increased ppGpp concentration in the gacA mutant.

\section{Altered Rsm sRNA levels in relA and spoT mutants.}

To determine whether ppGpp affects the function of the Gac/Rsm cascade, we determined the transcriptional expression of the $r \sin Y$ and $r \sin Z$ sRNA genes by introducing the transcriptional fusions rsmY-lacZ (chromosomal) or rsmZ-lacZ (on a plasmid) into relA and spoT mutants. The expression of both fusions was markedly reduced in the relA spoT double mutant but to a lesser extent than in the gacA mutant. In the spoT mutant, the expression levels were slightly increased, whereas those in the relA mutant were slightly decreased (Fig. 3A and B). In the rich medium used (nutrient yeast broth [NYB]), all the mutants grew at wild-type rates (Fig. 3E). These data suggest that, in a $g_{a c A^{+}}$background, ppGpp itself has a positive, probably indirect effect on the expression of the Rsm sRNAs.

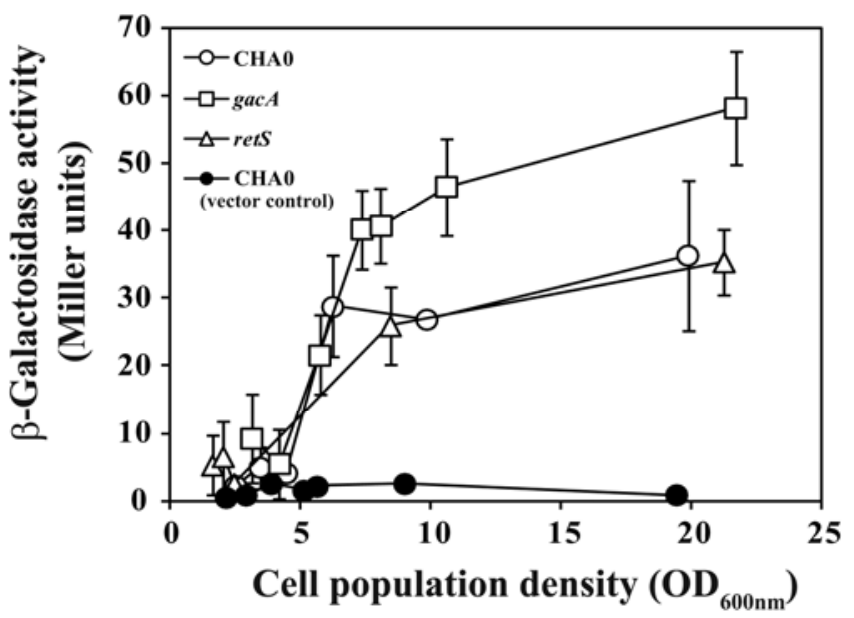

Fig. 2. Expression of a relA' - IacZ fusion on pME6014relA in CHA0, the gacA mutant $\mathrm{CHA} 89$, and the retS mutant CHA1202 grown in fullstrength glycerol-casamino acids medium. CHA0 harboring the empty vector pME6014 was included as vector control. The symbols indicate averages of triplicate cultures and bars indicate standard deviations. $\mathrm{OD}_{600 \mathrm{~nm}}=$ optical density at $600 \mathrm{~nm}$. 


\section{A relA spoT double mutant exhibits decreased} gacS and gacA expression.

Because the relA spoT double mutant of CHA0 showed attenuated levels of $\operatorname{rsm} Y$ and $r \sin Z$, we wondered whether this effect would be due to an effect of ppGpp on the expression of the GacS/GacA system. Indeed, the expression of translational gac $S^{\prime}-\eta a c Z$ and $g a c A^{\prime}-\eta a c Z$ fusions was downregulated in the relA spoT mutant by comparison with the wild type (Supple- mentary Fig. S6); however, this effect was less drastic than that on the sRNA genes (Fig. 3A and B).

\section{A relA spot double mutant exhibits decreased} aprA and rpoS expression.

In $P$. fluorescens $\mathrm{CHA} 0$, the GacS/GacA system positively controls the translational expression of aprA, the gene for the major exoprotease, and $r p o S$, the gene for the stationary phase
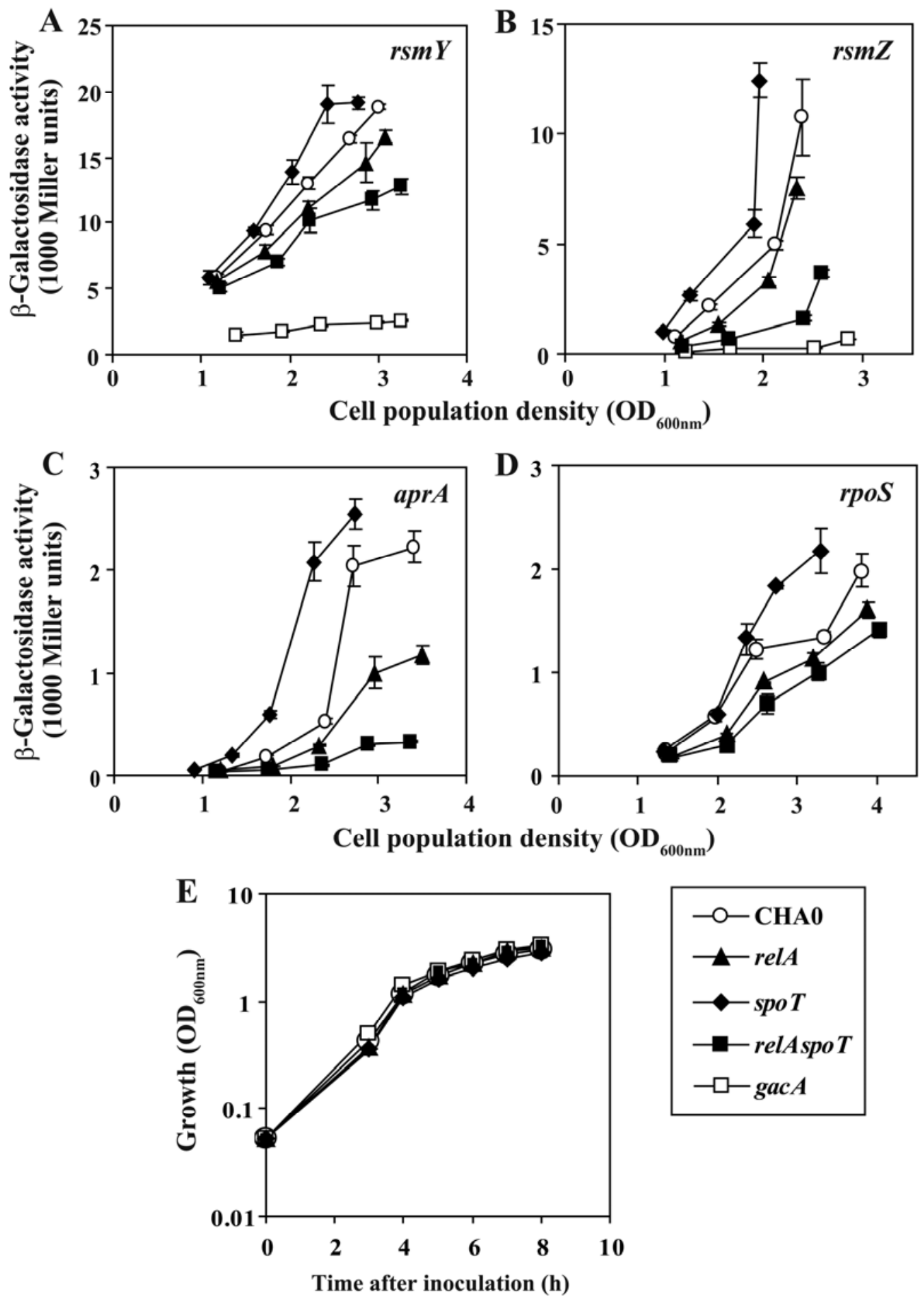

Fig. 3. Effects of relA and spoT mutations on the expression of the $r s m Y$, rsmZ, aprA, and rpoS genes. Transcriptional expression of A, a chromosomal rsmYlacZ fusion and B, a plasmid-borne rsmZ-lacZ fusion on pME6091 was determined in Pseudomonas fluorescens CHA0 (wild type, open circles), relA mutant (closed triangles), spoT mutant (closed diamonds), relA spoT mutant (closed squares) and gacA mutant $\mathrm{CHA} 89$ (open squares). Expression of C, a translational aprA'- - $a c Z$ fusion on pME6060 and D, an rpoS' - १acZ fusion on pME6355 was followed similarly in the relA and spoT mutants. E, Growth of each strain in the same medium (nutrient yeast broth) was monitored in parallel. Incubation was carried out in Erlenmeyer flasks. Measurements were carried out in triplicate. Symbols indicate averages and the error bars indicate standard deviations. OD $_{600 \mathrm{~nm}}=$ optical density at $600 \mathrm{~nm}$. 
and stress $\sigma$ factor (Heeb et al. 2005; Takeuchi et al. 2009). Therefore, we followed the expression of a translational aprA'

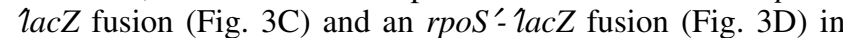
the relA and spoT mutants. The effects of these mutations were consistent with the ppGpp accumulation levels and the $\operatorname{rsm} Y$ and $r s m Z$ expression data. In particular, the relA spoT double mutant gave low aprA (Fig. 3C) and rpoS (Fig. 3D) expression, which is in agreement with the positive activity of ppGpp on the function of the Gac/Rsm pathway.

\section{A relA spoT double mutant exhibits decreased antibiotic activity, swarming motility, and biocontrol efficacy.}

We also wondered whether the relA spoT system would affect antibiotic activity and swarming motility of $P$. fluorescens CHA0. For the detection of antibiotic activity, strains were grown at $30^{\circ} \mathrm{C}$ on a glucose medium (NBGlu), which is conducive to 2,4-diacetyl-phloroglucinol (DAPG) production, and on a glycerol medium (NBGly), which favors pyoluteorin production in $P$. fluorescens Pf-5 (Kidarsa et al. 2011). The relA spoT double mutant had no detectable antibiotic activity on the NBGlu plate and reduced activity on the NBGly plate (Fig. 4A). The relA single mutant showed an attenuated level of antibiotic activity on the NBGlu plate, whereas this strain was not affected on the NBGly plate. These results suggest that ppGpp can affect the production of DAPG and, to a lesser extent, that of pyoluteorin. We also performed the same antibiotic assay at $26^{\circ} \mathrm{C}$, which is the temperature used in the biocontrol assays described later, and found the same inhibition pattern (data not shown).
The relA spoT double mutant showed a decreased level of swarming motility (Fig. 4B) relative to that of the wild type. We also note that the double mutant formed a thicker edge of the colony on a swarming plate (Fig. 4B). With respect to the swarming phenotype, the single relA mutant was similar to the wild-type CHA0 (Fig. 4B), suggesting that perhaps the residual (and undetectable) level of ppGpp in the relA mutant may be sufficient for this function.

The results obtained with the Rsm sRNA genes, antibiotic activity tests, and motility tests indicate that ppGpp influences the biocontrol capacity of $P$. fluorescens $\mathrm{CHA} 0$. To investigate the influence of the relA and spoT mutations in a natural habitat, we adopted a cucumber-Pythium ultimum pathosystem, which enabled us to evaluate the plant protection efficacy by measuring the root weight and shoot weight. The relA spoT double mutant was less effective as a biocontrol agent than the wild type, with $\geq 95 \%$ confidence (Table 2 ). Furthermore, this mutant also had a decreased root colonization capacity in both the presence and absence of Pythium ultimum (Table 2). In conclusion, these results are consistent with an impaired function of the Gac/Rsm pathway in the double mutant.

\section{DISCUSSION}

In the present study, we established metabolomic profiles of gacA, retS, and fumA mutants of Pseudomonas fluorescens CHA0 in a rich, albeit dilute medium. At the time of sampling for metabolome analysis, cells had not exhausted all nutrients, although some preferred carbon and nitrogen sources originally present in the medium had been consumed (e.g., gluta-
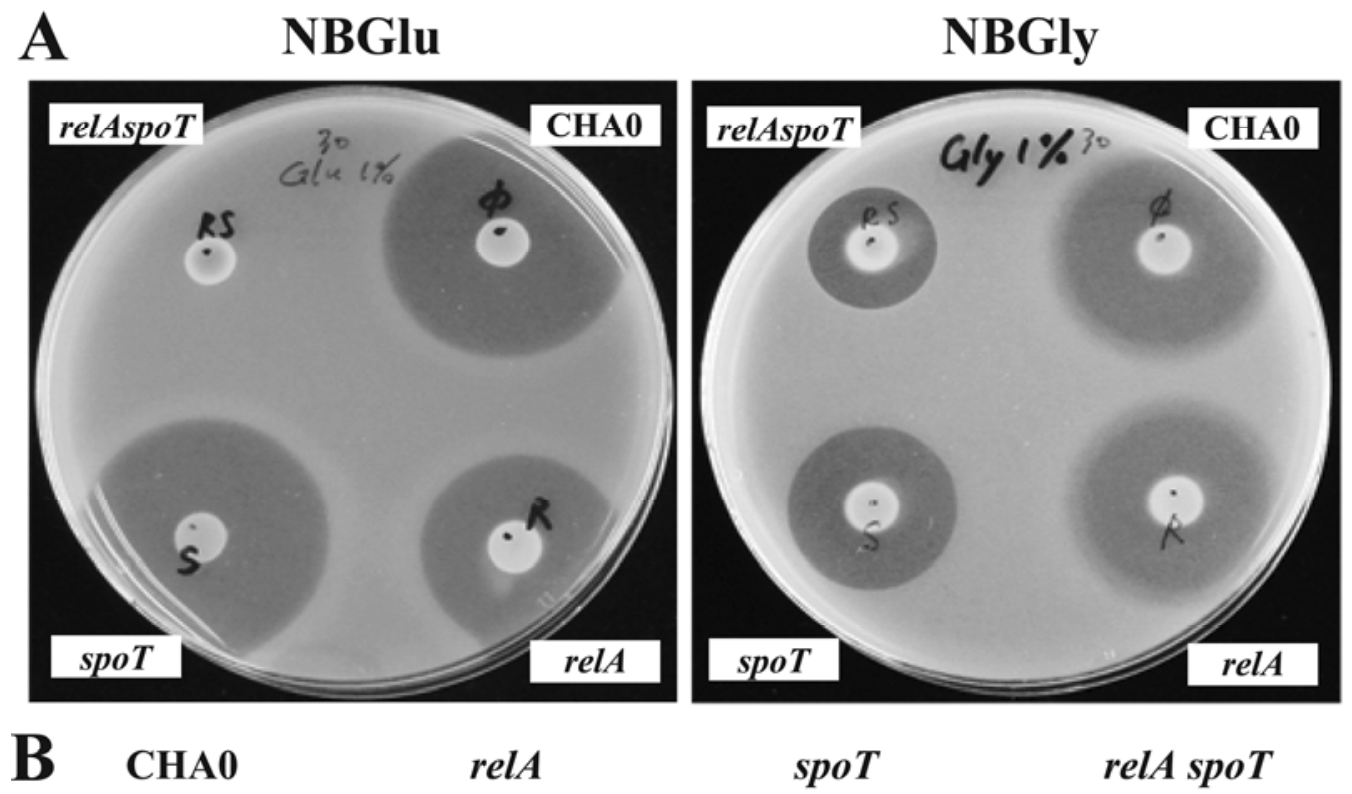

relA

spoT

relA spoT

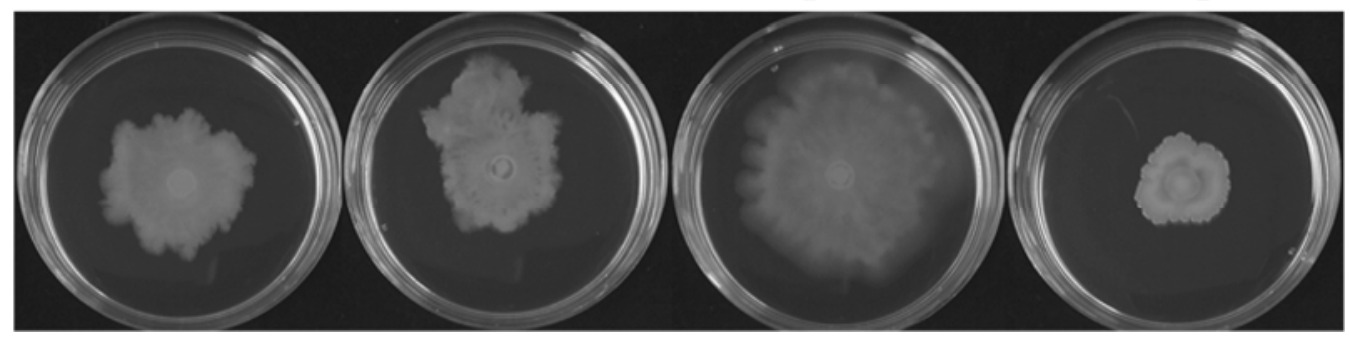

Fig. 4. Effects of relA and spoT mutations on antibiotic activity toward Bacillus subtilis and swarming motility. A, Antibiotic activities of Pseudomonas fluorescens strains grown on glucose medium (NBGlu, left) and glycerol medium (NBGly, right) plates were evaluated by the size of the growth inhibition zone of B. subtilis. Antibiotic activities of $P$. fluorescens CHA0 wild type, relA mutant, spoT mutant, and relA spoT mutant were compared on each plate incubated at $30^{\circ} \mathrm{C}$ for $16 \mathrm{~h}$. B, Swarming motility of $P$. fluorescens $\mathrm{CHA} 0$ and the relA and spoT mutants on Luria-Bertani plates containing $0.5 \%$ agar. Photographs were taken $24 \mathrm{~h}$ after inoculation. 
mate, proline, histidine, and aspartate) (Takeuchi et al. 2009). Thus, although cells were not growing optimally, they did not experience drastic amino acid limitation, a condition that typically elicits the stringent response. Therefore, we were surprised to find that the intracellular metabolite that was most strongly regulated by GacA under these conditions was ppGpp (Fig. 1A). The ppGpp concentration was elevated in the gacA mutant and reduced in the retS mutant, relative to that in the wild type (Fig. 1A; Table 1). Our methods did not allow us to quantify pppGpp, a minor RelA product; and, in this respect an uncertainty remains. Furthermore, the temperature $\left(30^{\circ} \mathrm{C}\right)$ chosen for our metabolomic analysis and the in vitro expression studies differs from the temperature used for the biocontrol assay $\left(26^{\circ} \mathrm{C}\right)$ and from the temperature range that root-colonizing pseudomonads normally encounter in nature. It is quite possible that the metabolomic profiles of the wild-type and the mutants might be different at temperatures around $20^{\circ} \mathrm{C}$.

Among 218 metabolites detected, we also found that several compounds related to arginine metabolism were markedly affected by the gacA and retS mutations in an opposite manner (Fig. 1). The intracellular pools of arginine, its precursors $\mathrm{N}$-acetyl-glutamate and $\mathrm{N}$-acetyl-ornithine, and its degradation products 4-guanidinobutyrate, 4-aminobutyrate (GABA), and urea (Haas et al. 1990) all went up significantly in the gacA mutant (Fig. 1A). These effects are not understood at present. Arginine has many functions in Pseudomonas spp. and more work will be required to figure out the significance of regulation by the Gac system. Furthermore, the gacA mutation affected purine and pyrimidine metabolism, primarily by increasing the levels of the purine degradation products hypoxanthine, urate, allantoate, and urea (Fig. 1A). In this context, there is a precedent that deserves to be mentioned: $N$-acyl homoserine lactones (quorum-sensing signals) positively control purine degradation in $P$. aeruginosa (Heurlier et al. 2005). Strain CHA0 does not have homoserine lactones but the Gac/Rsm pathway can be regarded as a quorumsensing regulatory mechanism. It is possible that, during the transition from fast growth to slow growth (i.e., during activation of the Gac system), some RNAs and, hence, purines and pyrimidines may be degraded. If the Gac system were involved in positively controlling purine degradation in strain CHA0, then the observed accumulation of intermediates of purine degradation in the gacA mutant could, indeed, be expected. Some effects of gacA and retS mutations on pyrimidine metabolism (UDPglucuronate, dCTP, and dCDP) were seen (Fig. 1A) but are difficult to rationalize at present.
Three further metabolomic findings deserve a comment. First, in E. coli, the RsmA homologue CsrA regulates central carbon metabolism (Babitzke and Romeo 2007). We find no clear-cut evidence for an analogous role in P. fluorescens (i.e., opposite effects of gacA and retS mutations on metabolites of central C metabolism) (Fig. 1). Second, two nonprotein amino acids, 3-hydroxyaspartate and 2,4-diaminobutyrate, were undetectable in the gacA mutant and overproduced in the retS mutant (Fig. 1). Although 2,4-diaminobutyrate is a building block in pyoverdine biosynthesis, we are not aware of the function of 3-hydroxyaspartate in strain CHA0. Third, the fact that GABA accumulated in the gacA mutant and was relatively depleted in the retS mutant (Fig. 1) is particularly intriguing, because GABA has been reported to be a signal capable of modulating quorum sensing in Agrobacterium tumefaciens (Chevrot et al. 2006). More work is needed to find out whether GABA may also have a function as a signal molecule in $P$. fluorescens CHA0. In conclusion, the metabolic changes found in the gacA and retS mutants imply that the Gac/Rsm signal transduction pathway has a profound impact on primary metabolism in strain CHA0, a fact that was previously not appreciated.

In the remainder of the present study, we focused on the role of ppGpp in the Gac/Rsm pathway and in biocontrol of $P$. fluorescens $\mathrm{CHA0}$. By comparison with the wild type, the relA spoT mutant of strain CHA0 showed markedly attenuated expression of RsmY and RsmZ (Fig. 3A and B) and, as a consequence, lower expression of traits regulated by these sRNAs: the AprA protease (Fig. 3C), the RpoS $\sigma$ factor (Fig. 3D), antibiosis (Fig. 4), and biocontrol efficacy (Table 2). The salient features of this regulation are summarized in a model (Fig. 5). The stimulating effect of ppGpp on the function of the Gac/Rsm pathway in $P$. fluorescens has similar counterparts in L. pneumophila and E. coli. In the latter two organisms, ppGpp has been found to exert indirect positive effects on the signal transduction pathways initiated by the GacS/GacA homologues LetS/LetA and BarA/UvrY, respectively (Edwards et al. 2011; Molofsky and Swanson 2004). In all three organisms, there is circumstantial evidence that the effect of ppGpp may be due, at least in part, to induction or activation of the $\mathrm{GacS} / \mathrm{GacA}$ two-component system; however, other mechanisms are not excluded. The fact that the spoT mutant of strain CHA0 showed increased expression levels of the $\operatorname{rsm} Y, \operatorname{rsmZ}$, aprA, and $\operatorname{rpoS}$ genes compared with the wild-type levels (Fig. 3) supports the model according to which ppGpp activates the

Table 2. Effects of relA and spoT mutations on the suppression of Pythium damping-off and root rot of cucumber by Pseudomonas fluorescens $\mathrm{CHA}^{\mathrm{x}}$

\begin{tabular}{|c|c|c|c|c|c|}
\hline \multirow[b]{2}{*}{ Bacterial strain } & \multirow[b]{2}{*}{ Pythium added } & \multicolumn{3}{|c|}{ Per flask ${ }^{y}$} & \multirow[b]{2}{*}{ Colonization $\left(\log _{10} \mathrm{CFU} / \mathrm{g}\right)^{2}$} \\
\hline & & Surviving plants (\%) & Shoot fresh weight (g) & Root fresh weight (g) & \\
\hline None & - & $100 \mathrm{a}$ & $0.99 \mathrm{a}$ & $0.22 \mathrm{ab}$ & ND \\
\hline CHA0 (wild type) & _- & $100 \mathrm{a}$ & $1.08 \mathrm{a}$ & $0.25 \mathrm{a}$ & $7.56 \pm 0.25 \mathrm{c}$ \\
\hline$\Delta r e l A$ & - & $100 \mathrm{a}$ & $0.99 \mathrm{a}$ & $0.22 \mathrm{ab}$ & $7.12 \pm 0.28 c$ \\
\hline$\Delta s p o T$ & _- & $100 \mathrm{a}$ & $1.00 \mathrm{a}$ & $0.22 \mathrm{ab}$ & $7.42 \pm 0.27 \mathrm{c}$ \\
\hline ArelAspot & - & $100 \mathrm{a}$ & $1.07 \mathrm{a}$ & $0.23 \mathrm{ab}$ & $6.15 \pm 0.26 \mathrm{~d}$ \\
\hline None & + & $17 \mathrm{~d}$ & $0.41 \mathrm{~d}$ & $0.10 \mathrm{c}$ & ND \\
\hline CHA0 (wild type) & + & $71 \mathrm{~b}$ & $0.74 \mathrm{~b}$ & $0.20 \mathrm{ab}$ & $8.68 \pm 0.23 \mathrm{a}$ \\
\hline$\Delta r e l A$ & + & $77 \mathrm{~b}$ & $0.78 \mathrm{~b}$ & $0.17 \mathrm{~b}$ & $8.69 \pm 0.29 a$ \\
\hline$\Delta$ spot & + & $75 \mathrm{~b}$ & $0.74 \mathrm{~b}$ & $0.19 \mathrm{~b}$ & $8.52 \pm 0.29 \mathrm{ab}$ \\
\hline DrelAspot & + & $52 \mathrm{c}$ & $0.59 \mathrm{c}$ & $0.12 \mathrm{c}$ & $7.77 \pm 0.45 \mathrm{bc}$ \\
\hline
\end{tabular}

${ }^{\mathrm{x}}$ P. fluorescens strains were added at $10^{7} \mathrm{CFU} / \mathrm{g}$ of soil contained within 100-ml flasks (30 g of soil/flask), after planting three 92-h-old, sterile-grown cucumber seedlings per flask. Pythium ultimum was added as a millet-seed inoculum at $2.5 \mathrm{~g} / \mathrm{kg}$ of soil before planting. Plants were harvested after 7 days.

${ }^{y}$ Data represent the averages of 11 replicates (flasks containing three cucumber plants) per treatment without Pythium ultimum and 22 replicates per treatment with Pythium ultimum. The control (uninfested plants not treated with $P$. fluorescens) was done in 20 replicates. Data represent the means from two individual repetitions of the same experiment. Means within the same column followed by different letters are significantly different $(P<0.05)$ according to Fisher's protected least significant difference (LSD) test.

${ }^{z}$ Colonization by $P$. fluorescens in CFU/g of root. The rhizosphere-stable plasmid pME6031 containing a tetracycline resistance determinant (Heeb et al. 2000) was introduced as a selective marker into the bacterial strains to determine their root colonization capacity in soil. ND = not detected. Means within the same column followed by different letters are significantly different $(P<0.05)$ according to Fisher's protected LSD test. 
Gac/Rsm pathway (Fig. 5) and suggests that SpoT functions mainly as a ppGpp hydrolase when RelA is present.

Our observation that ppGpp levels were enhanced in the gacS and gacA mutants and attenuated in the rsmA rsmE mutant (Table 1) points to a positive regulatory effect of the RsmA/E proteins in strain CHA0 (Fig. 5). However, the slight derepressing effect of the gacA mutation on relA' - lacZ expression (Fig. 2) cannot adequately explain these findings, and more work will be needed to elucidate this aspect of the regulatory cascade. By contrast, a gacS mutant of the biocontrol agent Pseudomonas sp. DF41 produced less (p)ppGpp (Manuel et al. 2011) and a $\operatorname{csr} A$ (homologue of $r s m A$ ) mutant of $E$. coli produced more (p)ppGpp than did the wild type (Edwards et al. 2011). It appears that different organisms have evolved different ways to control ppGpp levels via the Gac/Rsm pathway.

The relA spoT double mutant of strain $\mathrm{CHA} 0$ showed decreased root colonization in nonsterile soil in both the presence and absence of Pythium ultimum (Table 2). This mutant also exhibited decreased swarming motility (Fig. 4B). There are precedents for these observations. In many pathogenic bacteria, $\mathrm{ppGpp}$ contributes to their virulence such as invasiveness and persistence in the host (Braeken et al. 2006; Dalebroux et al. 2010). In L. pneumophila, for instance, a ppGpp-negative mutant shows decreased expression of its flagellar subunit gene flaA (Zusman et al. 2002). In P. aeruginosa, whose $\mathrm{Gac} / \mathrm{Rsm}$ system is similar to that of CHA0, ppGpp has a positive effect on swarming and virulence determinants such as pyocyanin and siderophores (Vogt et al. 2011). In P. putida, a strain overexpressing a diguanylate cyclase was simultaneously affected in swarming motility and root colonization
(Matilla et al. 2011). Likewise, in the case of CHA0, it is conceivable that the relA spoT double mutant was handicapped in the rhizosphere, in which bacterial motility is important for root colonization and in which fluctuating nutrient conditions result in a risk of depletion of vital molecules. Therefore, the compromised plant protection efficacy of the relA spoT mutant may be due not only to the decreased antibiotic activity but also to the relatively poor epiphytic fitness.

\section{MATERIALS AND METHODS}

\section{Bacterial strains and growth conditions.}

The bacterial strains and plasmids used are listed in Table 3. Strains of E. coli and P. fluorescens were routinely grown in NYB $(2.5 \%$ [wt/vol] nutrient broth and $0.5 \%$ [wt/vol] yeast extract) and Luria-Bertani (LB) medium with shaking, or on nutrient agar plates $(4 \%$ [wt/vol] blood agar base and $0.5 \%$ [wt/vol] yeast extract) amended with the following antibiotics when required: ampicillin, $100 \mu \mathrm{g} / \mathrm{ml}$ (only for $E$. coli); gentamicin, $50 \mu \mathrm{g} / \mathrm{ml}$; kanamycin, $25 \mu \mathrm{g} / \mathrm{ml}$; or tetracycline, 25 $\mu \mathrm{g} / \mathrm{ml}(125 \mu \mathrm{g} / \mathrm{ml}$ for selection of $P$. fluorescens $)$. For metabolome analyses, bacteria were grown in diluted and modified GCM to minimize the effects of the medium on the analysis (Takeuchi et al. 2009). The modified medium contained, per liter: casamino acids (Bacto), $1.5 \mathrm{~g}$; glycerol, $1.0 \mathrm{~g} ; \mathrm{K}_{2} \mathrm{HPO}_{4}$, $0.038 \mathrm{~g} ; \mathrm{MgSO}_{4} \cdot 7 \mathrm{H}_{2} \mathrm{O}, 0.15 \mathrm{~g}$; and $\mathrm{FeSO}_{4} \cdot 7 \mathrm{H}_{2} \mathrm{O}, 1 \mathrm{mg}$. When relevant, 5-bromo-4-chloro-3-indolyl- $\beta$-D-galactopyranoside was added to plates at a final concentration of $0.02 \%$. The inoculation temperatures were $30^{\circ} \mathrm{C}$ for $P$. fluorescens and $37^{\circ} \mathrm{C}$ for E. coli. P. fluorescens was grown at $35^{\circ} \mathrm{C}$ to improve

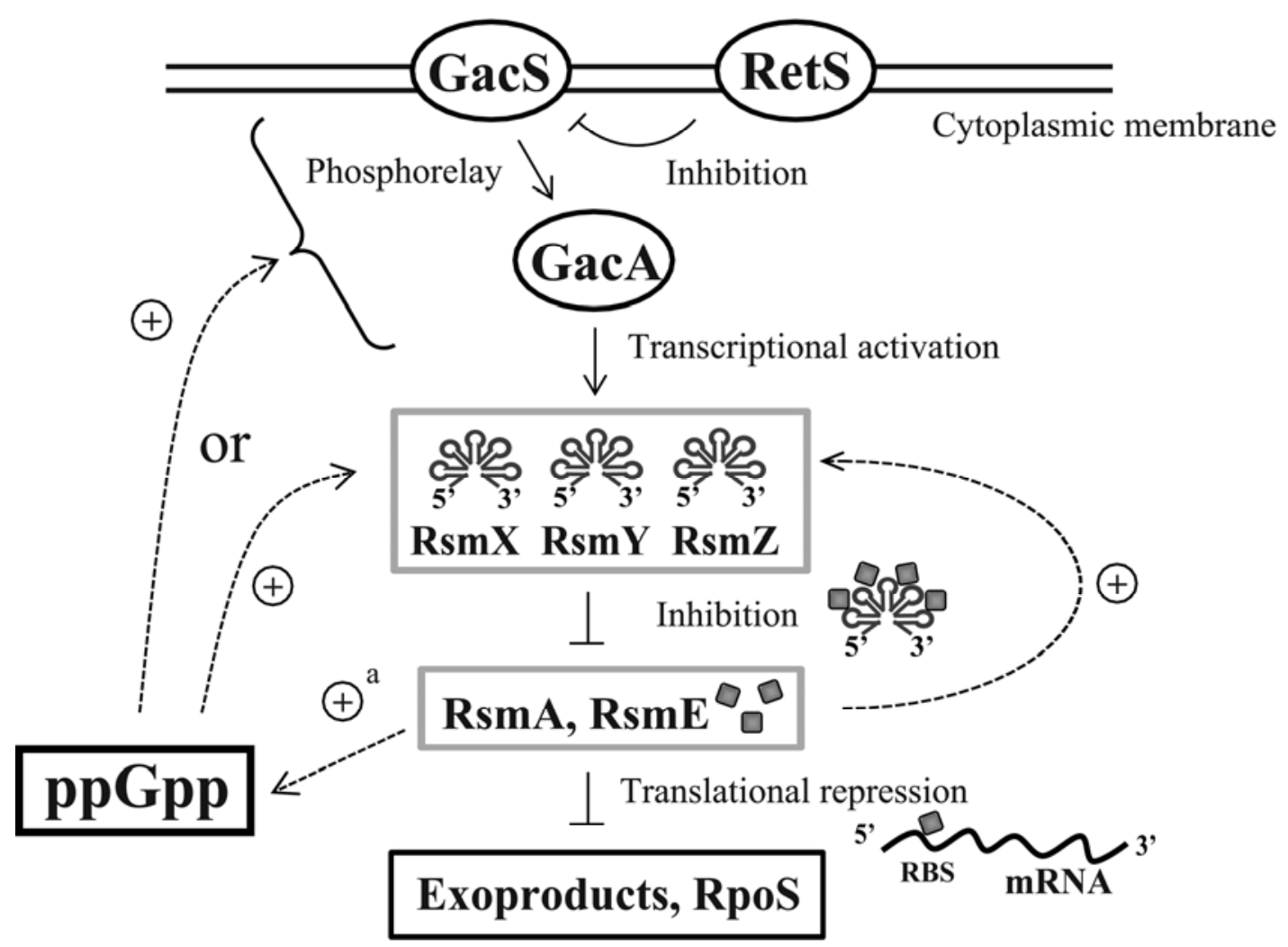

Fig. 5. Model for gene regulation by guanosine tetraphosphate (ppGpp) in the Gac/Rsm system of Pseudomonas fluorescens CHA0. Evidence for this pathway comes from this work and from previous studies (Heeb et al. 2002, 2005; Kay et al. 2005; Reimmann et al. 2005; Valverde et al. 2003). The new finding of this study is that ppGpp has a positive effect on the Gac/Rsm system. Nutrient limitation and stress are the major factors inducing ppGpp synthesis. Thus, when nutrients become scarce and under stress conditions, ppGpp activates the Gac/Rsm system. This will allow cells to expand their metabolic repertoire by excreting proteases and lipases and to restrict access of competing microorganisms by forming antibiotic compounds. The negative effect of the Gac/Rsm system on ppGpp formation has a modulating function and, presumably, avoids overshooting of secondary metabolism and exoenzyme production. Thus, the model postulates a negative (self-limiting) loop. Symbols: $\downarrow$, positive effect; $\stackrel{\perp}{\perp}$, negative effect; dotted lines, indirect effects; superscript a, it remains to be determined in detail how the Gac/Rsm pathway controls ppGpp levels via relA and, presumably, spoT expression. 
its capacity to accept heterologous DNA (e.g., in electrotransformation or in matings with $E$. coli). For some other assays, bacteria were grown in the normal GCM (Maurhofer et al. 1998). M9 glucose medium plates $\left(\mathrm{Na}_{2} \mathrm{HPO}_{4}, 12.8 \mathrm{~g} / \mathrm{liter}\right.$; $\mathrm{KH}_{2} \mathrm{PO}_{4}, 3.0$ g/liter; $\mathrm{NaCl}, 0.5$ g/liter; $\mathrm{NH}_{4} \mathrm{Cl}, 1.0 \mathrm{~g} /$ liter, $\mathrm{MgSO}_{4} \cdot 7 \mathrm{H}_{2} \mathrm{O}, 0.494 \mathrm{~g} /$ liter; thiamine, $0.01 \mathrm{~g} /$ liter; $\mathrm{CaCl}_{2}$. $2 \mathrm{H}_{2} \mathrm{O}, 0.015 \mathrm{~g} / \mathrm{liter}$; and glucose, $2.0 \mathrm{~g} /$ liter) were used to test growth of relA and spoT mutants of $P$. fluorescens. For detection of antibiotic activity, strains were grown on Difco Nutrient Broth (Becton, Dickinson and Company, Sparks, MD, U.S.A.) supplemented with either $1 \%(\mathrm{wt} / \mathrm{vol})$ glucose (NBGlu) or $1 \%$ (vol/vol) glycerol (NBGly) (Kidarsa et al. 2011).

\section{DNA manipulation.}

Small-scale plasmid extraction was carried out with a QIAprep spin miniprep kit (Qiagen, Hilden, Germany); large-scale preparations were obtained with a Qiagen plasmid midi kit (Qiagen). Chromosomal DNA from P. fluorescens was prepared as previously described (Gamper et al. 1992). DNA fragments were purified from agarose gels with a QIAquick gel extraction kit (Qiagen). Oligonucleotides used are listed in Supplementary Table S3.

\section{Construction of a $\mathrm{rel} A=1 \mathrm{acZ}$ fusion.}

A 420-bp PstI fragment from the upstream region of PFL 4446 was amplified using primers RelAProF and RelAProR, and inserted into pME6014 to obtain pME6014relA containing a translational relA' $-\eta a c Z$ fusion.

\section{Generation of $\mathrm{relA}$ - and spoT-negative mutants.}

In-frame deletions in the chromosomal relA and spoT genes of $P$. fluorescens $\mathrm{CHA} 0$ were created as follows. Fragments of approximately $750 \mathrm{bp}$ located on each side of the relA or spoT gene were amplified by PCR with primer pairs RelAUF/ RelAUR and RelADF/RelADR for relA or SpoTUF/SpoTUR and SpoTDF/SpoTDR for spoT. Each two corresponding fragments were annealed and amplified as $1.5-\mathrm{kb}$ fragments using primers RelAUF/RelADR or SpoTUF/SpoTDR, respectively. After sequencing, these $1.5-\mathrm{kb}$ fragments were cloned into pME3087 cut with BamHI and HindIII to give pME3087relA and pME3087spoT. These plasmids were mobilized from $E$. coli $\mathrm{DH} 5 \alpha$ to $P$. fluorescens $\mathrm{CHA} 0$ by triparental mating with E. coli HB101/pME497. Excision of the vector via a second crossing-over was obtained after enrichment for tetracyclinesensitive cells (Humair et al. 2009), generating the relA or spoT mutant. To delete the spoT gene in the relA mutant, the pME3087 spoT plasmid was mobilized to the relA mutant as recipient strain. Construction of a gacA relA double mutant and a gacA relA spoT triple mutant were created utilizing a gacA mutant as the parental strain.

\section{$\boldsymbol{\beta}$-Galactosidase assays.}

$\beta$-Galactosidase activities were quantified by the Miller method (Miller, 1972). P. fluorescens strains were grown at $30^{\circ} \mathrm{C}$ in $50-\mathrm{ml}$ flasks containing $20 \mathrm{ml}$ of NYB amended with $0.05 \%$ Triton X-100 with shaking at $180 \mathrm{rpm}$. Triton X-100 was required to prevent cell aggregation.

\section{Metabolite extraction procedure.}

$P$. fluorescens strains were grown in $20 \mathrm{ml}$ of diluted and modified GCM in 50-ml Erlenmeyer flasks with shaking at $180 \mathrm{rpm}$ and $30^{\circ} \mathrm{C}$. For each strain, three cultures were incubated in parallel. Samples were taken from each culture during the idiophase (at $\mathrm{OD}_{600}$ of approximately 1.7), when maximal

Table 3. Bacterial strains and plasmids used in this study

\begin{tabular}{|c|c|c|}
\hline Strain or plasmid & Description $^{\mathrm{z}}$ & Source or reference \\
\hline \multicolumn{3}{|l|}{ Strains } \\
\hline Bacillus subtilis, M168 & Wild type & C. Keel \\
\hline Escherichia coli, DH5 $\alpha, \mathrm{HB} 101$ & Laboratory strains & Sambrook and Russell 2001 \\
\hline \multicolumn{3}{|l|}{ Pseudomonas fluorescens } \\
\hline CHA0 & Wild type & Stutz et al. 1986 \\
\hline CHA19 & $\Delta g a c S$ & Zuber et al. 2003 \\
\hline CHA89 & $\operatorname{gacA}:: \mathrm{Km}^{\mathrm{r}} ; \mathrm{Km}^{\mathrm{r}}$ & Laville et al. 1992 \\
\hline CHA1008 & 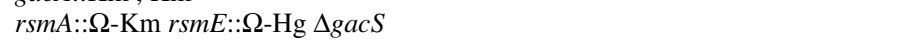 & Reimmann et al. 2005 \\
\hline CHA1009 & 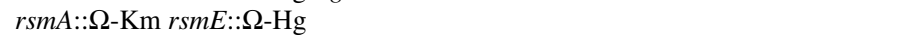 & Reimmann et al. 2005 \\
\hline CHA1202 & $\Delta r e t S$ & Humair et al. 2009 \\
\hline CHA1322 & $\Delta$ fumA & Takeuchi et al. 2009 \\
\hline CHAOrelA & $\Delta r e l A$ & This study \\
\hline CHA0spoT & $\Delta s p o T$ & This study \\
\hline CHA0relAspoT & $\Delta r e l A \Delta$ spoT & This study \\
\hline CHA89relA & gacA $:: \mathrm{Km}^{\mathrm{r}} \Delta$ relA & This study \\
\hline CHA89relAspoT & gacA $:: \mathrm{Km}^{\mathrm{r}} \Delta$ relA $\Delta$ spoT & This study \\
\hline \multicolumn{3}{|l|}{ Plasmids } \\
\hline pBluescript II KS & Cloning vector, ColE1 replicon; $\mathrm{Ap}^{\mathrm{r}}$ & Stratagene \\
\hline pME497 & Mobilizing plasmid, IncP-1, Tra, RepA(Ts); $\mathrm{Ap}^{\mathrm{r}}$ & Voisard et al. 1988 \\
\hline pME3087 & Suicide vector, ColE1 replicon, Mob; $\mathrm{Tc}^{\mathrm{r}}$ & Voisard et al. 1994 \\
\hline pME3087relA & pME3087 containing a BamHI/HindIII $1.5-\mathrm{kb}$ relA region containing a deletion & 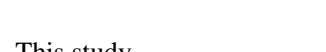 \\
\hline pME3087spoT & $\begin{array}{l}\text { pME3087 containing a BamHI/HindIII } 1.5-\mathrm{kb} \text { spoT region containing a deletion } \\
\text { of } 1.3 \mathrm{~kb} \text { in the spoT gene; } \mathrm{Tc}^{\mathrm{r}}\end{array}$ & This study \\
\hline pME3266 & Translational gac $S^{\prime}-\eta a c Z$ fusion; $\mathrm{Tc}^{\mathrm{r}}$ & F. Carruthers \\
\hline pME6014 & Cloning vector for construction of translational $l a c Z$ fusions; $\mathrm{Tc}^{\mathrm{r}}$ & Schnider-Keel et al. 2000 \\
\hline pME6014relA & Translational relA' - \{acZ fusion under ptac; $\mathrm{Tc}^{\mathrm{r}}$ & This study \\
\hline pME6031 & pACYC177-pVS1 shuttle vector; $\mathrm{Tc}^{\mathrm{r}}$ & Heeb et al. 2000 \\
\hline pME6060 & Translational aprA' - ใacZ fusion; $\mathrm{Tc}^{\mathrm{r}}$ & Blumer et al. 1999 \\
\hline pME6091 & Transcriptional $r s m Z$-lacZ fusion; $\mathrm{Tc}^{\mathrm{r}}$ & Heeb et al. 2002 \\
\hline pME6355 & Translational rpoS'- - $a c Z$ fusion; $\mathrm{Tc}^{\mathrm{r}}$ & Heeb et al. 2005 \\
\hline pME6827 & 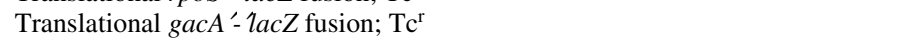 & C. Reimmann \\
\hline pME7699 & $\begin{array}{l}\text { Transcriptional } r s m Y \text {-lacZ fusion in mini-Tn7 gene delivery vector pME6182; } \\
\mathrm{Gm}^{\mathrm{r}} \mathrm{Ap}^{\mathrm{r}}\end{array}$ & Humair et al. 2009 \\
\hline
\end{tabular}

${ }^{\mathrm{z}} \mathrm{Km}^{\mathrm{r}}, \mathrm{Ap}^{\mathrm{r}}, \mathrm{Tc}^{\mathrm{r}}$, and $\mathrm{Gm}^{\mathrm{r}}$ indicate resistance to kanamycin, ampicillin, tetracycline, or gentamicin, respectively. 
rsmZ-lacZ expression was observed. Cells were harvested by vacuum filtration through a $0.4-\mu \mathrm{m}$ pore size filter. The cells on the filter (calculated as $\mathrm{OD}_{600} \times$ sampling volume of culture in milliliters of approximately 24) were washed twice with $5 \mathrm{ml}$ of Milli-Q water. The filter was immersed in $2 \mathrm{ml}$ of methanol, including $10 \mu \mathrm{M}$ Internal Standard Solution 1 (Human Metabolome Technologies, Tsuruoka, Japan). The filter was sonicated for $30 \mathrm{~s}$ using a Branson ultrasonic bath to suspend the cells completely. A $1.6-\mathrm{ml}$ portion of the methanol cell suspension was transferred to a 15-ml centrifuge tube (Falcon Blue Max Jr. 352097; Becton Dickinson \& Co., Franklin Lakes, NJ, U.S.A.) and mixed with $1.6 \mathrm{ml}$ of chloroform and $640 \mu \mathrm{l}$ of Milli-Q water. After vortexing well, the mixture was centrifuged at $2,300 \times g$ at $4^{\circ} \mathrm{C}$ for $5 \mathrm{~min}$. The aqueous layer was distributed to three Amicon Ultrafree-MC ultrafilter tips (Millipore Co., Bedford, MA, U.S.A.) and centrifuged at $9,100 \times g$ and $4^{\circ} \mathrm{C}$ for approximately $2 \mathrm{~h}$. The filtrate was dried and preserved at $-80^{\circ} \mathrm{C}$ until CE-TOFMS analysis. Prior to analysis, the sample was dissolved in $25 \mu \mathrm{l}$ of Milli-Q water.

\section{CE-TOFMS.}

CE-TOFMS was carried out using a capillary electrophoresis system equipped with a TOF mass spectrometer (Agilent Technologies, Waldbronn, Germany). Separations and detections of metabolites were basically performed as described previously for cationic metabolites (Soga and Heiger 2000; Soga et al. 2003) and anionic metabolites (Soga et al. 2002, 2003).

Cationic metabolites were analyzed with a fused silica capillary, with cation buffer solution (Human Metabolome Technologies) as the electrolyte. The sample was injected at a pressure of 50 mbar for $10 \mathrm{~s}$. The applied voltage was set at $27 \mathrm{kV}$. Electrospray ionization (ESI)-MS was conducted in the positive ion mode, and the capillary voltage was set at 4,000 V.

Anionic metabolites were also analyzed with a fused silica capillary, with anion buffer solution (Human Metabolome Technologies) as the electrolyte. The sample was injected at a pressure of 50 mbar for $25 \mathrm{~s}$. The applied voltage was set at $30 \mathrm{kV}$. ESI-MS was conducted in the negative ion mode, and the capillary voltage was set at $3,500 \mathrm{~V}$.

For all analytical modes, the inner diameter and total length of capillary were $50 \mu \mathrm{m}$ and $80 \mathrm{~cm}$, respectively. Exact mass data were acquired over a range of 50 to $1,000 \mathrm{~m} / \mathrm{z}$. Raw data were processed using the KEIO MasterHands software, ver. 2.1.0.1 (Sugimoto et al. 2010). Metabolites in the samples were identified by comparison of the migration time and $\mathrm{m} / \mathrm{z}$ ratio with those of authentic standards, in which a difference of \pm 0.5 min and \pm 10 ppm, respectively, was permitted and quantified by comparing peak areas with those of the authentic standards using ChemStation software (Agilent Technologies). Principal component analyses were performed with MATLAB 2007a (The Math Works, Natick, MA, U.S.A.).

\section{HPLC assay of ppGpp.}

Intracellular levels of ppGpp were determined in $P$. fluorescens strains cultured in diluted and modified GCM. Samples were prepared from each culture with the same method of metabolite extraction procedure as described above. The intracellular concentration of ppGpp was determined by HPLC on a Waters system (Waters, Milford, MA, U.S.A.) consisting of photodiode array detector 996 and pump 616, equipped with a normal phase column (TSKgel Amide-80, 4.6 by $250 \mathrm{~mm}$; Tosoh, Tokyo). Isocratic elution was performed with $65 \%$ (vol/vol) acetonitrile and 35\% (vol/vol) $75 \mathrm{mM}$ potassium phosphate buffer ( $\mathrm{pH} 4.5)$ at a flow rate of $1.0 \mathrm{ml} / \mathrm{min}$. Nucleotides were detected at $254 \mathrm{~nm}$. ppGpp was detected with a retention time of $29.0 \pm 0.5 \mathrm{~min}$ and its concentration was expressed relative to cell density $\left(\mathrm{OD}_{600}\right.$ of approximately $1.0 / \mathrm{ml})$. The ppGpp standard ( $>95 \%$ pure) was obtained from TriLink Biotechnologies (San Diego, CA, U.S.A.).

\section{Detection of antibiotic activity.}

Antibiotic activity of $P$. fluorescens strains grown on NBGlu or NBGly plates containing $1.8 \%$ agar was determined with Bacillus subtilis M168 as the reporter. Cultures of P. fluorescens were adjusted to $\mathrm{OD}_{600}=1.5$ and $5-\mu$ l samples were spotted onto the plate. After overnight incubation at $30^{\circ} \mathrm{C}$, cells were killed by UV irradiation on a transilluminator for $5 \mathrm{~min}$. An overlay of B. subtilis revealed antibiotic production by growth-inhibition zones.

\section{Swarming motility assay.}

Cells from overnight cultures grown in NYB were adjusted to an $\mathrm{OD}_{600}=1.0$ with water and $2-\mu \mathrm{l}$ aliquots were spotted onto semisolid LB agar $(0.5 \%)$ plates. The plates were incubated at room temperature for $24 \mathrm{~h}$ and swarming motility was assessed qualitatively by examining the circular halo formed by the motile bacterial cells.

\section{Plant disease suppression and root colonization assays.}

Flasks containing $30 \mathrm{~g}$ of a 1:1 mixture of nonsterile horticultural soil (Kureha, Tokyo) and vermiculite were planted with three cucumber seedlings each and treated with either Pythium ultimum MAFF425494, Pseudomonas fluorescens, or both. $P$. fluorescens strains were added to soil as a suspension $(3 \mathrm{ml} /$ flask) of cells washed twice in sterile distilled water to give $1 \times$ $10^{7} \mathrm{CFU} / \mathrm{g}$ of soil. Control flasks received the same amount of sterile water. Seedlings were covered with $5 \mathrm{~g}$ of nontreated soil and flasks were sealed with aerated silicon caps. The microcosms were incubated in a growth chamber at $60 \%$ relative humidity and $26^{\circ} \mathrm{C}$ with light for $16 \mathrm{~h}$, followed by an 8-h dark period. No watering was necessary. After 7 days of incubation, the biocontrol activity and root colonization of each strain were assessed. Data in Table 2 represent the means from two individual repetitions of the same experiment. Data of both experiments were first analyzed for trial-by-treatment interaction by analysis of variance, which indicated that the data from the two independent trials could be pooled. Means were separated with Fisher's protected least significant difference test $(P \leq$ 0.05). Data for CFU counts were $\log _{10}$-transformed prior to statistical analysis. Statistical analysis was performed with the SPSS Statistics software (IBM, Tokyo).

\section{ACKNOWLEDGMENTS}

This work was supported by Grants-in-Aid for Young Scientists (B) 22780042 and 24780045 from the Japan Society for the Promotion of Science.

\section{LITERATURE CITED}

Babitzke, P., and Romeo, T. 2007. CsrB sRNA family: sequestration of RNA-binding regulatory proteins. Curr. Opin. Microbiol. 10:156-163.

Blumer, C., Heeb, S., Pessi, G., and Haas, D. 1999. Global GacA-steered control of cyanide and exoprotease production in Pseudomonas fluorescens involves specific ribosome binding sites. Proc. Natl. Acad. Sci. U.S.A. 96:14073-14078.

Boes, N., Schreiber, K., and Schobert, M. 2008. SpoT-triggered stringent response controls usp gene expression in Pseudomonas aeruginosa. J. Bacteriol. 190:7189-7199.

Braeken, K., Moris, M., Daniels, R., Vanderleyden, J., and Michiels, J. 2006. New horizons for (p)ppGpp in bacterial and plant physiology. Trends Microbiol. 14:45-54.

Chevrot, R., Rosen, R., Haudecoeur, E., Cirou, A., Shelp, B.J., Ron, E., and Faure, D. 2006. GABA controls the level of quorum-sensing signal in Agrobacterium tumefaciens. Proc. Natl. Acad. Sci. U.S.A. 103:74607464 
Dalebroux, Z. D., Svensson, S. L., Gaynor, E. C., and Swanson, M. S. 2010. ppGpp conjures bacterial virulence. Microbiol. Mol. Biol. Rev. 74:171-199.

Edwards, A. N., Patterson-Fortin, L. M., Vakulskas, C. A., Mercante, J. W., Potrykus, K., Vinella, D., Camacho, M. I., Fields, J. A., Thompson, S. A., Georgellis, D., Cashel, M., Babitzke, P., and Romeo, T. 2011. Circuitry linking the $\mathrm{Csr}$ and stringent response global regulatory systems. Mol. Microbiol. 80:1561-1580.

Gamper, M., Ganter, B., Polito, M. R., and Haas, D. 1992. RNA processing modulates the expression of the $\operatorname{arcDABC}$ operon in Pseudomonas aeruginosa. J. Mol. Biol. 226:943-957.

Goodman, A. L., Merighi, M., Hyodo, M., Ventre, I., Filloux, A., and Lory, S. 2009. Direct interaction between sensor kinase proteins mediates acute and chronic disease phenotypes in a bacterial pathogen. Genes Dev. 23:249-259.

Haas, D., and Défago, G. 2005. Biological control of soil-borne pathogens by fluorescent pseudomonads. Nat. Rev. Microbiol. 3:307-319.

Haas, D., Galimand, M., Gamper, M., and Zimmermann, A. 1990. Arginine network of Pseudomonas aeruginosa: Specific and global controls. Pages 303-316 in: Pseudomonas: Biotransformations, Pathogenesis and Evolving Biotechnology. S. Silver, A. M. Chakrabarty, B. Iglewski, and S. Kaplan, eds. ASM Press, Washington DC.

Heeb, S., Itoh, Y., Nishijyo, T., Schnider, U., Keel, C., Wade, J., Walsh, U., O'Gara, F., and Haas, D. 2000. Small, stable shuttle vectors based on the minimal pVS1 replicon for use in gram-negative, plant-associated bacteria. Mol. Plant-Microbe Interact. 13:232-237.

Heeb, S., Blumer, C., and Haas, D. 2002. Regulatory RNA as mediator in GacA/RsmA-dependent global control of exoproduct formation in Pseudomonas fluorescens CHA0. J. Bacteriol. 184:1046-1056.

Heeb, S., Valverde, C., Gigot-Bonnefoy, C., and Haas, D. 2005. Role of the stress sigma factor RpoS in GacA/RsmA-controlled secondary metabolism and resistance to oxidative stress in Pseudomonas fluorescens CHA0. FEMS (Fed. Eur. Microbiol. Soc.) Microbiol. Lett. 243:251258.

Heurlier K., Dénervaud V., Haenni, M., Guy, L., Krishnapillai, V., and Haas, D. 2005. Quorum sensing-negative (lasR) mutants of Pseudomonas aeruginosa avoid cell lysis and death. J. Bacteriol. 187:4875-4883.

Humair, B., González, N., Mossialos, D., Reimmann, C., and Haas, D. 2009. Temperature-responsive sensing regulates biocontrol factor expression in Pseudomonas fluorescens CHA0. ISME J. 3:955-965.

Kay, E., Dubuis, C., and Haas, D. 2005. Three small RNAs jointly ensure secondary metabolism and biocontrol in Pseudomonas fluorescens CHA0. Proc. Natl. Acad. Sci. U.S.A. 102:17136-17141.

Kay, E., Humair, B., Dénervaud, V., Riedel, K., Spahr, S., Eberl, L., Valverde, C., and Haas, D. 2006. Two GacA-dependent small RNAs modulate the quorum-sensing response in Pseudomonas aeruginosa. J. Bacteriol. 188:6026-6033.

Kidarsa, T. A., Goebel, N. C., Zabriskie, T. M., and Loper, J. E. 2011. Phloroglucinol mediates cross-talk between the pyoluteorin and 2,4diacetylphloroglucinol biosynthetic pathways in Pseudomonas fluoresens Pf-5. Mol. Microbiol. 81:395-414.

Kim, Y. C., Leveau, J., McSpadden Gardener, B. B., Pierson, E. A., Pierson, L. S., III, and Ryu, C. M. 2011. The multifacterorial basis for plant health promotion by plant-associated bacteria. Appl. Environ. Microbiol. 77:1548-1555

Lapouge, K., Schubert, M., Allain, F. H.-T., and Haas, D. 2008. Gac/Rsm signal transduction pathway of $\gamma$-proteobacteria: from RNA recognition to regulation of social behaviour. Mol. Microbiol. 67:241-253.

Laville, J., Voisard, C., Keel, C., Maurhofer, M., Défago, G., and Haas, D. 1992. Global control in Pseudomonas fluorescens mediating antibiotic synthesis and suppression of black root rot of tobacco. Proc. Natl. Acad. Sci. U.S.A. 89:1562-1566.

Manuel, J., Berry, C., Selin, C., Fernando, W. G., and de Kievit, T. R. 2011. Repression of the antifungal activity of Pseudomonas sp. strain DF41 by the stringent response. Appl. Environ. Microbiol. 77:5635-5642.

Matilla, M. A., Travieso, M. I., Ramos, J. L., and Ramos-González, M. I. 2011. Cyclic diguanylate turnover mediated by the sole GGDEF/EAL response regulator in Pseudomonas putida: its role in the rhizosphere and an analysis of its target processes. Environ. Microbiol. 13:17451766

Maurhofer, M., Reimmann, C., Schmidli-Sacherer, P., Heeb, S., Haas, D., and Défago, G. 1998. Salicylic acid biosynthetic genes expressed in Pseudomonas fluorescens strain P3 improve the induction of systemic resistance in tobacco against tobacco necrosis virus. Phytopathology 88:678-684.

Miller, J. H. 1972. Experiments in Molecular Genetics. Cold Spring Har- bor Laboratory Press, Cold Spring Harbor, NY, U.S.A.

Molofsky, A. B., and Swanson, M. S. 2004. Differentiate to thrive: lessons from the Legionella pneumophila life cycle. Mol. Microbiol. 53:29-40.

Murphy, H., and Cashel, M. 2003. Isolation of RNA polymerase suppressors of a (p)ppGpp deficiency. Methods Enzymol. 371:596-601.

Potrykus, K., and Cashel, M. 2008. (p)ppGpp: still magical? Annu. Rev. Microbiol. 62:35-51.

Reimmann, C., Valverde, C., Kay, E., and Haas, D. 2005. Posttranscriptional repression of GacS/GacA-controlled genes by the RNA-binding protein RsmE acting together with RsmA in the biocontrol strain Pseudomonas fluorescens CHA0. J. Bacteriol. 187:276-285.

Sambrook, J., and Russell, D. W. 2001. Molecular Cloning: A Laboratory Manual, 3rd ed. Cold Spring Harbor Laboratory Press, Cold Spring Harbor, NY, U.S.A.

Schnider-Keel, U., Seematter, A., Maurhofer, M., Blumer, C., Duffy, B., Gigot-Bonnefoy, C., Reimmann, C., Notz, R., Défago, G., Haas, D., and Keel, C. 2000. Autoinduction of 2,4-diacetylphloroglucinol biosynthesis in the biocontrol agent Pseudomonas fluorescens CHA0 and repression by the bacterial metabolites salicylate and pyoluteorin. J. Bacteriol. 182:1215-1225.

Soga, T., and Heiger, D. N. 2000. Amino acid analysis by capillary electrophoresis electrospray ionization mass spectrometry. Anal. Chem. $72: 1236-1241$

Soga, T., Ueno, Y., Naraoka, H., Ohashi, Y., Tomita, M., and Nishioka, T. 2002. Simultaneous determination of anionic intermediates for Bacillus subtilis metabolic pathways by capillary electrophoresis electrospray ionization mass spectrometry. Anal. Chem. 74:2233-2239.

Soga, T., Ohashi, Y., Ueno, Y., Naraoka, H., Tomita, M., and Nishioka, T. 2003. Quantitative metabolome analysis using capillary electrophoresis mass spectrometry. J. Proteome Res. 2:488-494.

Stutz, E. W., Défago, G., and Kern, H. 1986. Naturally occurring fluorescent Pseudomonads involved in suppression of black root rot of tobacco. Phytopathology 76:181-185.

Sugimoto, M., Wong, D. T., Hirayama, A., Soga, T., and Tomita, M. 2010. Capillary electrophoresis mass spectrometry-based saliva metabolomics identified oral, breast and pancreatic cancer-specific profiles. Metabolomics 6:78-95.

Takeuchi, K., Kiefer, P., Reimmann, C., Keel, C., Dubuis, C., Rolli, J., Vorholt, J. A., and Haas, D. 2009. Small RNA-dependent expression of secondary metabolism is controlled by Krebs cycle function in Pseudomonas fluorescens. J. Biol. Chem. 284:34976-34985.

Valverde, C., Heeb, S., Keel, C., and Haas, D. 2003. RsmY, a small regulatory RNA, is required in concert with RsmZ for GacA-dependent expression of biocontrol traits in Pseudomonas fluorescens CHA0. Mol. Microbiol. 50:1361-1379.

Vogt, S. L., Green, C., Stevens, K. M., Day, B., Erickson, D. L., Woods, D. E., and Storey, D. G. 2011. The stringent response is essential for Pseudomonas aeruginosa virulence in the rat lung agar bead and Drosophila melanogaster feeding models of infection. Infect. Immun. 79:40944104

Voisard, C., Rella, M., and Haas, D. 1988. Conjugative transfer of plasmid RP1 to soil isolates of Pseudomonas fluorescens is facilitated by certain large RP1 deletions. FEMS (Fed. Eur. Microbiol. Soc.) Microbiol. Lett. 55:9-13.

Voisard, C., Bull, C. T., Keel, C., Laville, J., Maurhofer, M., Schnider, U., Défago, G., and Haas, D. 1994. Biocontrol of root diseases by Pseudomonas fluorescens $\mathrm{CHA0}$ : current concepts and experimental approaches. Pages 67-89 in: Molecular Ecology of Rhizosphere Microorganisms. F. O'Gara, D. N. Dowling, and B. Boesten, eds. VCH, Weinheim, Germany.

Workentine, M. L., Chang, L., Ceri, H., and Turner, R. J. 2009. The GacSGacA two-component regulatory system of Pseudomonas fluorescens: A bacterial two-hybrid analysis. FEMS (Fed. Eur. Microbiol. Soc.) Microbiol. Lett. 292:50-56.

Zuber, S., Carruthers, F., Keel, C., Mattart, A., Blumer, C., Pessi, G., GigotBonnefoy, C., Schnider-Keel, U., Heeb, S., Reimmann, C., and Haas, D. 2003. GacS sensor domains pertinent to the regulation of exoproduct formation and to the biocontrol potential of Pseudomonas fluorescens CHA0. Mol. Plant-Microbe Interact. 16:634-644.

Zusman, T., Gal-Mor, O., and Segal, G. 2002. Characterization of a Legionella pneumophila relA insertion mutant and roles of RelA and RpoS in virulence gene expression. J. Bacteriol. 184:67-75.

\section{AUTHOR-RECOMMENDED INTERNET RESOURCE}

Pseudomonas Genome database: www.pseudomonas.com 